\title{
CRYSTALLIZATION PARAMETERS OF NON-CRYSTALLINE ANTIMONY CHALCOGENIDES
}

\author{
V. M. Rubish, M. V. Dobosh, P. P. Shtets, I. I. Shpak, \\ V. V. Rubish, I. M. Yurkin, D. G. Semak, V. I. Fedelesh \\ Uzhgorod National University, 54 Voloshyn St., Uzhgorod, UA-88000, Ukraine
}

(Отримано 2003 р.)

\begin{abstract}
The results of studying the kinetics of non-isothermic crystallization of Sb-S-I glasses are given. By DTA and DerTA methods the characteristic temperatures of thermal effects $T_{g}, T_{c}, T_{m}$ have been investigated. The activation energies of originating nuclei of crystals $\Delta G_{A 0}$ and their growth $\Delta G_{A M}$ have been calculated from temperatures begining at $T_{C 0}$ and maximum $T_{C M}$ of the crystallization effect as a function of the heating rate $q$. The critical radii for nuclei of crystals $r_{c}$ and amorphization radii $r_{a}$ are calculated. The crystallizability of melts depending on the composition has been studied. The compositions from the regions of eutectics have been shown to possess a minimal crystallizability, and those ones in the vicinity of $\mathrm{Sb}_{2} \mathrm{~S}_{3}$ and SbSI stoichiometric compounds possess a maximal one. The results obtained are being discussed proceeding from the peculiarities of the structure of studied materials.
\end{abstract}

Key words: chalcogenide glass, crystallization, activation energy.

PACS number(s): 73.61.Jc

\section{INTRODUCTION}

The unique combination of diverse properties in chalcogenide glassy semiconductors conditions a wide range of their practical application. Non-crystalline antimony chalcogenides and chalcohalogenides ( $\mathrm{Sb}-\mathrm{S}(\mathrm{Se})-$ $\mathrm{I}(\mathrm{Br})$ systems) are very promising in this aspect. Due to high photoconductivity and light sensitivity, specific optical properties, the existence of a polar state the glasses of these systems can serve as the initial material for creating the media of optical information recording, radiation indicators, optical elements of IR technique, highvoltage supply sources, ferroelectric glass-ceramics [1-5]. However, preparing these materials in a glassy state is connected with some difficulties because of a high crystallization ability of their melts. As the calculations and experiments have shown the majority of glasses in $\mathrm{Sb}$ $\mathrm{S}(\mathrm{Se})-\mathrm{I}(\mathrm{Br})$ systems may be prepared under the conditions of hard quenching (at cooling rates of melts equal to $100-300 \mathrm{~K} / \mathrm{s}[4,6])$. The crystallization of the glasses of indicated systems is very specific, too. That is why it is necessary to study the mechanisms and kinetics of "meltglass" and "glass-crystal" phase transitions. The study of crystallization processes of glasses allows one to qualitatively connect relaxation and kinetic parameters with critical cooling rates of the melt in the glass-formation process, to develop technological regimes of preparing glasses with reproducible parameters, high stability and thermal resistance, to define optimal regimes of preparing ferroelectric glass-ceramics.

In the present report the results of studying the kinetics of non-isothermic crystallization of Sb-S-I glasses $\left(\mathrm{Sb}-\mathrm{S}\right.$ and $\mathrm{Sb}_{2} \mathrm{~S}_{3}-\mathrm{SbI}_{3}$ sections) are given.

\section{EXPERIMENTAL METHODS}

The glasses under study were synthesized by the method of vacuum fusion of purity elements in ac- cordance with the methods given in $[4,6,7]$. Different methods of quenching melts allowed us to prepare $\mathrm{Sb}_{x} \mathrm{~S}_{1-x}$ alloys with antimony content up to $35-45$ at.\% and $\left(\mathrm{Sb}_{2} \mathrm{~S}_{3}\right)_{y}\left(\mathrm{SbI}_{3}\right)_{1-y}$ alloys with iodine content up to 33.3 at. $\%$ in a glassy state.

By the DTA method [8] at heating rates $q=0.08$; $0.17 ; 0.25$ and $0.33 \mathrm{~K} / \mathrm{s}$ the characteristic temperatures of thermal effects of glasses were studied (temperatures of glass-formation $T_{g}$, crystallization $T_{c}$, melting $T_{m}$ ). The crystallization process is characterized by temperatures of the exothermic effect begining of crystallization $T_{C O}$ and maximal growth rate of a crystalline phase $T_{C M}$. In many cases it is very difficult to unambiguously define these temperatures by the DTA method.

That is why while studying the non-isothermic crystallization of $\mathrm{Sb}_{x} \mathrm{~S}_{1-x}$ and $\left(\mathrm{Sb}_{2} \mathrm{~S}_{3}\right)_{y}\left(\mathrm{SbI}_{3}\right)_{1-y}$ glasses the DerTA method [9] was used by us which possesses more expressed singularities in thermograms and allows one to determine temperatures of thermal effects with a larger accuracy. The accuracy of temperature determination made up $\pm 0.5 \mathrm{~K}$.

\section{RESULTS AND DISCUSSION}

In Fig. 1 DTA and DerTA thermograms of some glassy alloys of Sb-S-I system (typical for all studied materials) at heating rates of $0.08 \mathrm{~K} / \mathrm{s}$ are given. Softening, crystallization and melting effects of a crystallized phase are observed in these curves. The concentrational dependences of characteristic temperatures $T_{g}, T_{c}$ and $T_{m}$ are given in Fig. 2. The value of $T_{c}$ corresponds to the maximum of crystallization. It should be noted that the composition trend of a curve $T_{c}$ agrees well with the liquidus curve of a stable phase diagram of $\mathrm{Sb}_{2} \mathrm{~S}_{3}-\mathrm{SbI}_{3}$ system [10]. The similar situation is observed in $\mathrm{Sb}-\mathrm{S}$ system [11]. With increasing the iodine content in the composition of glasses the crystallization and melting effects get noticeably 
complicated. While introducing a small amount of $\mathrm{SbI}_{3}$ additional crystallization and melting effects appear in DTA and DerTA curves (Fig.1, curves 3, 3'). With increasing the iodine content these effects increase in amplitude. At this the decrease in $T_{g}$ and $T_{c}$ (Fig. 2) is observed.

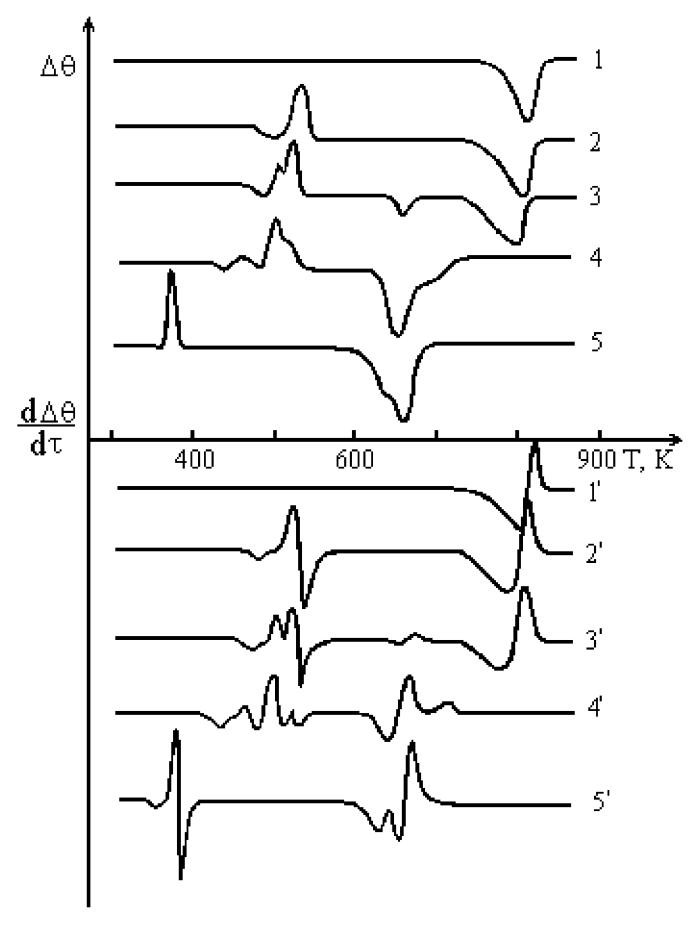

Fig. 1. DTA $(1-5)$ and DerTA $\left(1^{\prime}-5^{\prime}\right)$ curves of glasses in Sb-S-I system. $1,1^{\prime}$ - crystalline $\mathrm{Sb}_{2} \mathrm{~S}_{3} ; 2,2^{\prime}-\mathrm{Sb}_{0.40} \mathrm{~S}_{0.60}$; $3,3^{\prime}-\mathrm{Sb}_{0.39} \mathrm{~S}_{0.59} \mathrm{I}_{0.02} ; \quad 4,4^{\prime}-\mathrm{Sb}_{0.37} \mathrm{~S}_{0.48} \mathrm{I}_{0.15} ; \quad 5,5^{\prime}-$ $\mathrm{Sb}_{0.33} \mathrm{~S}_{0.33} \mathrm{I}_{0.33}$.

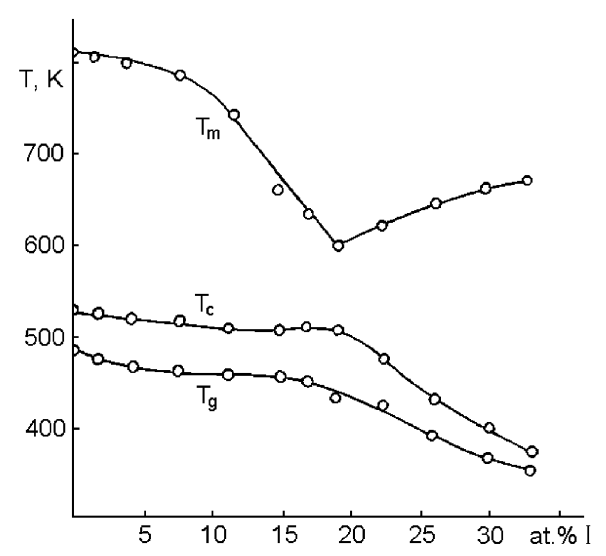

Fig. 2. Dependences $T_{g}, T_{c}, T_{m}$ of $\left(\mathrm{Sb}_{2} \mathrm{~S}_{3}\right)_{y}\left(\mathrm{SbI}_{3}\right)_{1-y}$ glasses vs composition.

A complex character of thermograms speaks in favour of a microheterogenic model of the structure of glasses of $\mathrm{Sb}-\mathrm{S}-\mathrm{I}$ system. The structure of $\mathrm{Sb}_{x} \mathrm{~S}_{1-x}$ glass- es is determined by a random two-dimensional network structure whose main element is $\mathrm{SbS}_{3 / 2}$ trigonal pyramid [5]. The presence of excess antimony and iodine promotes the formation of a complicated spacially branched quasieutectic structure [12]. At high temperatures in $\left(\mathrm{Sb}_{2} \mathrm{~S}_{3}\right)_{y}\left(\mathrm{SbI}_{3}\right)_{1-y}$ glasses the activated complexes with the structure close to that of a crystalline SbSI may appear. The formation of such high-polarized complexes was revealed while studying dielectric properties and IRspectra of glassy SbSI [3, 7].

The availability of some structural units promotes the glass-formation in Sb-S-I system. However, in the region of a ternary compound (SbSI) it sharply decreases due to suppression of relaxation and kinetic factors by the processes that result in the thermodynamic balance. The indirect proof of increasing the crystallization ability of glasses with $y>0.25$ is a considerable increase in their $T_{g}$ and $T_{c}$ (Fig. 2). The crystallization ability of glasses may be estimated with the help of the parameter introduced by Hruby [13]

$$
K_{G}=\frac{T_{c}-T_{g}}{T_{m}-T_{c}} .
$$

The larger the difference $T_{c}-T_{g}$ and the smaller the temperature interval $T_{m}-T_{c}$, the less is the probability of the fact that when heating the glass it will crystallize. The dependences of $K_{G}$ vs composition are given in Fig. 3. It is seen that the maximal value of this parameter $\left(K_{G}=0.60\right)$ in $\mathrm{Sb}_{2} \mathrm{~S}_{3}-\mathrm{SbI}_{3}$ system is for the alloy of eutectic composition $(y=0.25)$. The glasses of stoichiometric composition $\mathrm{Sb}_{2} \mathrm{~S}_{3}(0.15)$ and SbSI (0.10) possess minimal values of $K_{G}$. In Sb-S system the parameter $K_{G}$ varies within the limits of $0.15-0.20$ and non-stoichiometric glassy $\mathrm{Sb}_{x} \mathrm{~S}_{1-x}$ alloys $(x \neq 0.40)$ have larger values of $K_{G}$.

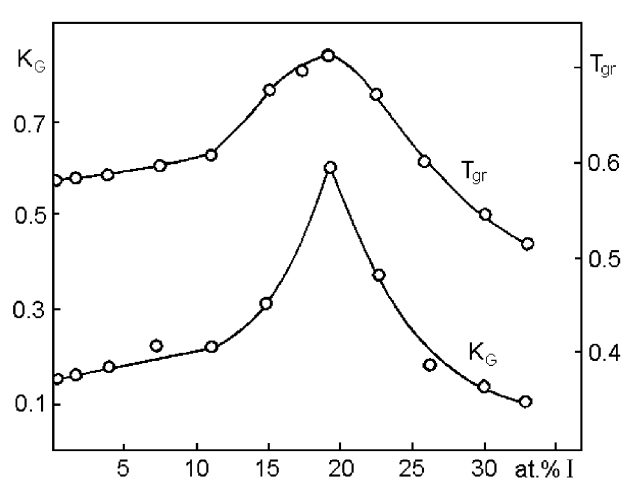

Fig. 3. Dependences of parameters $K_{G}$ and $T_{g r}$ of $\left(\mathrm{Sb}_{2} \mathrm{~S}_{3}\right)_{y}\left(\mathrm{SbI}_{3}\right)_{1-y}$ glasses vs composition.

It should be noted that for the majority of glassforming alloys of different chalcogenide systems a good correlation of the parameter $K_{G}$ with the reduced temperature of glass-formation $T_{g r}=T_{g} / T_{m}$ exists [14]. The glasses having a low crystallization ability are charac- 
terized by high values of $K_{G}$ and $T_{g r}$. In $\mathrm{Sb}-\mathrm{S}$ system the value of $T_{g r}$ while varying the composition does not practically change and is within the limits of $0.59-0.60$. In $\mathrm{Sb}_{2} \mathrm{~S}_{3}-\mathrm{SbI}_{3}$ system the glass of eutectic composition possesses the maximal value of $T_{g r}$ (iodine content makes up 19 at.\%) (Fig. 3) The data obtained testify to the fact that the glasses from the regions of eutectics possess the minimal crystallization ability in Sb-S-I system, and the glasses near stoichiometric $\mathrm{Sb}_{2} \mathrm{~S}_{3}$ and SbSI compounds have a maximal crystallization ability.

The kinetics of any phase transition is determined by the nucleation rate $(I)$ and the rate $(U)$ of subsequent growth of the size of the inhomogeneities of composition and structure. If the centres of crystallization are absent in the glass, it is necessary to take into account the rate of their spontaneous formation. In this case the inhomogeneities are nucleated by a fluctuation way. Because of the formation of the phase interface this nucleation is accompanied by a small time increase in the free energy of the system. The increase in the free energy may sometimes exceed its decrease connected with the crystallization that is the nuclei may be unstable. Stable nuclei are formed with a noticeable rate at certain overheating, which depends on relative magnitudes of the free energy of the phase interface and that of crystallization.

The behaviour of the nucleus depends on its size. It can grow or dissolve as both processes are accompanied by the decrease in the thermodynamic potential. The nucleus will grow if its radius is larger than some critical one. The radius of a critical nucleus $r_{c}$ may be determined from the relationship [15]

$$
r_{c}=\frac{2 \sigma T_{m} V}{\Delta H_{m} \Delta T},
$$

where $\sigma$ is the free energy on the interface crystalЦglass, $V$ is a molar volume, $\Delta H_{m}$ is a molar enthalpia of melting, $\Delta T=T_{m}-T$.

The specific free energy of surface tension $\sigma$ in accordance with the empiric approach of Skopski-Turnbull
[16] may be estimated from the formula

$$
\sigma=\frac{\beta \Delta H_{m}}{N_{\mathrm{A}}^{1 / 3} V^{2 / 3}} .
$$

Here $\beta$ is constant, for chalcogenides $\approx 0.2[6], N_{\mathrm{A}}-$ Avogadro's number.

If the nucleus radius of a crystalline phase is within the limits of $r_{c}<r<r_{a}$, the growth of nucleus is more favourable, though its presence in the system remains not energetically favourable, on the whole. The dimension of the nucleus with which the ordering process becomes favourable is given by the expression [15]:

$$
r_{a}=\frac{3 \sigma T_{m} V}{\Delta H_{m} \Delta T}
$$

The magnitude $r_{a}$ may be considered to be the smallest radius of stable crystals. It is often called the "amorphization radius". The nuclei formed begins to grow with the rate to be determined by the diffusion rate of atoms necessary for the crystal surface growth. The initial data and calculated radii $r_{c}$ and $r_{a}$ of some alloys of Sb-S-I system are given in Table 1. For comparison the similar data for $\mathrm{As}_{0.40} \mathrm{Se}_{0.60}$ alloy are given here. The data $r_{c}$ obtained for this glass correlate well with those determined earlier $\left(r_{c}=9 \AA\right)$ [17]. As a kinetic barrier of the crystallization the activation energy of viscous flow was used. As it is seen from Table 1, the alloy, which corresponds to stoichiometric SbSI has the smallest values of $r_{c}$ and $r_{a}$. It testifies to a very high crystallization ability of the given material and explains well an exclusive difficulty of preparing it in a glassy state.

Since the nucleation and growth of a new phase bear an activation character one should consider the process flow and matter of the activation energy of crystallization in accordance with the statements of the general theory for absolute reaction rates [18].

\begin{tabular}{|c|c|c|c|c|}
\hline Parameter & $\mathrm{Sb}_{0.40} \mathrm{~S}_{0.60}$ & $\mathrm{Sb}_{0.36} \mathrm{~S}_{0.45} \mathrm{I}_{0.19}$ & $\mathrm{Sb}_{0.33} \mathrm{~S}_{0.33} \mathrm{I}_{0.33}$ & $\mathrm{As}_{0.40} \mathrm{Se}_{0.60}$ \\
\hline \hline$T_{g}, \mathrm{~K}$ & 483 & 433 & 349 & 453 \\
\hline$T_{c}, \mathrm{~K}$ & 525 & 505 & 369 & 579 \\
\hline$T_{m}, \mathrm{~K}$ & 808 & 599 & 673 & 638 \\
\hline$\Delta H_{m}, \mathrm{~kJ} / \mathrm{mol}$ & 29.7 & 23.5 & 17.8 & 35.3 \\
\hline$\sigma \cdot 10^{3}, \mathrm{~J} / \mathrm{m}^{2}$ & 56 & 49 & 45 & 43 \\
\hline$r_{c} \cdot 10^{10}, \mathrm{~m}$ & 6.4 & 6.8 & 4.4 & 8.5 \\
\hline$r_{a} \cdot 10^{10}, \mathrm{~m}$ & 9.6 & 10.2 & 6.5 & 12.8 \\
\hline$\Delta G_{A 0}, \mathrm{~kJ} / \mathrm{mol}$ & 131 & 188 & 90 & 158 \\
\hline$\Delta G_{A M}, \mathrm{~kJ} / \mathrm{mol}$ & 114 & 176 & 82 & 146 \\
\hline
\end{tabular}

Table 1. Thermodinamic and crystallization parameters of glasses. 
The following equation is the basis for the experimental determination of kinetic parameters of the crystallization of glasses [19]

$$
\frac{d \alpha}{d \tau}=f(\alpha, T)
$$

Here $f(\alpha, T)$ is the quantity function of the matter $\alpha$ which changed into a crystalline state and temperature $T$ at the moment of time $\tau$. The rate of given off heat $d Q / d \tau \sim d a / d \tau$ may be recorded in the form of peaks in thermal analysis curves. Though the kinetic equation (5) depends on a definite mechanism of the reaction, one of its most used variants for the majority of processes has the form [20]

$$
\frac{d \alpha}{d \tau}=A(1-\alpha)^{n} \exp \left(-\frac{\Delta G_{A}}{R T}\right)
$$

Here $A$ is a pre-exponential factor (frequency factor), $n$ is the "order" of the reaction, $\Delta G_{A}$ is the activation energy of the process. Its essence is transforming a structural complex into an activated state along the direction of crystallization reaction.

Since the dependence of the characteristics upon heating rates is peculiar for kinetic flowing processes (with increasing $q$ the values of $T_{g}$ and $T_{c}$ increase), for definite points of DTA and DerTA curves of glasses one may estimate the activation energies of processes that take place in them with sufficient approximation [21].

In case of the first-order reaction $(n=1)$ by studying the reaction (6) for the extremum and taking the stationarity of the process into account Kissinger [22] got the relation

$$
\frac{d\left(\ln \left(q / T_{\mathrm{cmax}}^{2}\right)\right)}{d\left(1 / T_{\mathrm{cmax}}\right)}=-\frac{\Delta G_{A}}{R}
$$

where $R$ is an universal gas constant; $T_{\text {cmax }}$ is the extremum temperature in thermal analysis curve. By solving the equation graphically (7), we found the activation energy $\Delta G_{A}$ of the process under study.

In practice a somewhat modified variant of defining the activation energies is used [23]. Constructing the dependences of temperatures $T_{C O}$ and $T_{C M}$ of onset and maximum of crystallization thermal effect upon the rate of programmed heating $q$, we obtained the activation energies of crystallization from the relationship of the following kind:

$$
\begin{gathered}
\frac{1}{T_{C 0}}=C_{\mathrm{O}}-\frac{R}{\Delta G_{A 0}} \ln q, \\
\frac{1}{T_{C M}}=C_{M}-\frac{R}{\Delta G_{A M}} \ln \frac{q}{T_{C M}^{2}} .
\end{gathered}
$$

Here $C_{0}$ and $C_{M}$ are the constants which depend on the nature of a material and conditions of the experiment. The activation energies $\Delta G_{A 0}$ and $\Delta G_{A M}$ were determined according to the inclination of dependences $1 / T_{C 0}$ of $\ln q$ and $1 / T_{C M}$ of $\ln \left(q / T_{C M}^{2}\right)$. The results of calculations are shown in Fig. 4.

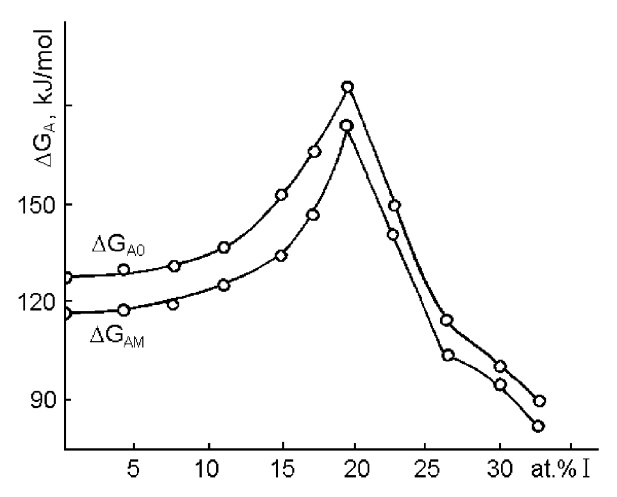

Fig. 4. Dependences of activation energies $\Delta G_{A 0}$ and $\Delta G_{A M}$ of $\left(\mathrm{Sb}_{2} \mathrm{~S}_{3}\right)_{y}\left(\mathrm{SbI}_{3}\right)_{1-y}$ glasses vs composition.

It is evident that at temperatures of the crystallization begining of glasses $T_{C 0}$ the part of activation energy, which forms crystal nuclei prevails in $\Delta G_{A 0}$. It includes the process of diffusion or reorientation of molecules into a right unit. At $T_{C M}$ the activation energy of the crystalline phase growth in $\Delta G_{A M}$ prevails.

As it is seen from Fig. 4 and Table 1, the activation energies of crystallization in $\mathrm{Sb}_{2} \mathrm{~S}_{3}-\mathrm{SbI}_{3}$ system greatly depend on the composition of glasses. Maximal values of $\Delta G_{A 0}$ and $\Delta G_{A M}$ are observed for the glass of eutectic composition $(y=0.25)$. Either with the increase or decrease of iodine content in the composition of glasses of $\mathrm{Sb}-\mathrm{S}-\mathrm{I}$ system these parameters greatly decrease and their crystallization ability increases. A stronger concentrational dependence of $\Delta G_{A 0}$ and $\Delta G_{A M}$ for glasses from $\mathrm{Sb}_{0.36} \mathrm{~S}_{0.45} \mathrm{I}_{0.19}-\mathrm{Sb}_{0.33} \mathrm{~S}_{0.33} \mathrm{I}_{0.33}$ region than for glasses with smaller iodine content should be mentioned. In Sb-S system the values of activation energies are within a considerably narrower interval $\left(\Delta G_{A 0}=\right.$ $\left.123.2 \div 130.6 \mathrm{~kJ} / \mathrm{mol}, \Delta G_{A M}=105.3 \div 110.8 \mathrm{~kJ} / \mathrm{mol}\right)$ and the maximum of $\Delta G_{A 0}$ and $\Delta G_{A M}$ is observed for the glass of stoichiometric composition $(x=0.40)$. Such behaviour of crystallization parameters of glasses may be explained on the basis of their local structure. As it was mentioned earlier, in the region of stable bulk glasses with $y<0.25$ the structure of $\left(\mathrm{Sb}_{2} \mathrm{~S}_{3}\right)_{y}\left(\mathrm{SbI}_{3}\right)_{1-y}$ glasses is quasieutectic and capable of forming polar structural units. In glasses depleted in iodine the main structural element is $\mathrm{SbS}_{3 / 2}$ trigonal pyramid. It is evident that regrouping of spacially coordinated $\mathrm{SbS}_{3 / 2}$ pyramids is more complicated. This results in more higher values of $\Delta G_{A 0}$ and $\Delta G_{A M}$ for the glasses close to $\mathrm{Sb}_{2} \mathrm{~S}_{3}$ by the composition than for those ones with high iodine content. The results obtained correlate well with the results of calculating $r_{c}$ and $r_{a}$ (Table 1). It is seen that the 
glasses with the smallest crystallization ability have the largest values of $r_{c}, r_{a}, \Delta G_{A 0}, \Delta G_{A M}$.

The analysis of preparing and crystallization conditions of the system under study has shown that the surface crystallization is typical for them. The free surface of the glass has larger probability of forming a thermally activated nucleus than the fluctuation origin of the nucleus in the glass bulk. In the process of non-isothermic heating the transition from surface to volume crystallization takes place. The given conclusion is confirmed by the results of studying chalcogenide glasses in a dispersed state [24]. While decreasing the sizes of grains both critical sizes of nuclei and activation energies of crystallization $\Delta G_{A 0}$ and $\Delta G_{A M}$ decrease, too.

\section{CONCLUSION}

As a result of this study and the conducted calculations it is established that the glasses of stoichiometric compositions $\left(\mathrm{Sb}_{2} \mathrm{~S}_{3}\right.$ and $\mathrm{SbSI}$ ) possess minimal values of activation energies of crystal nuclei origin $\Delta G_{A 0}$ and their growth $\Delta G_{A M}$ in Sb-S-I system. These compositions have the smallest critical radii of crystalline nuclei. The change in the composition of glasses is accompanied by the essential changes in thermodynamic and crystallization parameters. The glasses from the region of eutectics possess the smallest crystallization ability. Such a behaviour of parameters of the crystallization of Sb$\mathrm{S}-\mathrm{I}$ system is connected with the peculiarities of their structure.
[1] V. D. Kulibaba, V. A. Polishchuk, Elektronnaya teknika. Poluprovodnikovyye pribory 2, (175), 111 (1985).

[2] V. M. Rubish, P. P. Shtets, V. V. Rubish, V. I. Malesh, Ukr. J. Phys. Opt. 3, 130 (2002).

[3] V. M. Rubish, J. Optoelectron. Adv. Mat. 3, 941 (2001).

[4] I. D. Turianitsa, T. N. Melnichenko, P. P. Shtets, V. M. Rubish, Izv. Akad. Nauk SSSR, Neorgan. Materialy, 22, 2047 (1986).

[5] P. P. Shtets, D. I. Bletskan, I. D. Turianitsa, M. P. Bodnar, V. M. Rubish, Izv. Akad. Nauk SSSR, Neorg. Mater. 25, 933 (1989).

[6] V. A. Shtets, V. V. Rubish, V. I. Malesh, V. M. Rubish, D. G. Semak, J. Optoelectron. Adv. Mat. 4, 159 (2002).

[7] D. G. Turianitsa, A. A. Horvat, V. M. Rubish, M. V. Dobosh, Fiz. Tverd. Tela 27, 934 (1985).

[8] M. V. Shtets, V. P. Terban, N. V. Polazhinets, I. M. Yurkin, in Metrologicheskoye obespecheniye proiszvodstva i kontrolno-izmeritelnaya tekhnika, Uzhgorod, 3, 77 (1985).

[9] M. V. Dobosh, Fiz. Elektron. 16, 92 (1978).

[10] A. A. Riazantsev, A. A. Varekha, B. A. Popovkin, V. A. Liakhovitskaya, A. V. Novoselova, Izv. Akad. Nauk SSSR, Neorgan. Mater. 5, 1296 (1969).

[11] M. Hansen, K. Anderko, Structures of double alloys (Metalurgia, Moscow, 1962).

[12] V. M. Rubish, P. P. Shtets, V. V. Rubish, D. G. Semak,
Visn. Uzhgorod. univ., Ser. Fiz. 7, 58 (2000).

[13] U. Hruby, L. Stourač, Chech. J. Phys. 24, 1132 (1974).

[14] A. Felts, Amorphous and glassy non-organic solids (Mir, Moscow, 1986).

[15] D. R. Uhlmann, I. M. Stevels, J. Non-Cryst. Solids 7, 337 (1972).

[16] D. Turnbull, I. M. Cohen, in Modern aspects of the vitreous state, edited by S. D. Mackenzie, Butterworths $\mathbf{1}$, 38 (1960).

[17] E. V. Shkolnikov, Fiz. Khim. Stekla 6, 282 (1980).

[18] S. Glaston, K. Leidler, G. Eiring, Theory of absolute rates of reactions (Inostrannaya lit-ra, Moscow, 1948).

[19] P. D. Garn, in Proceeding Fourth JCTA, Budapest 1, 25 (1974).

[20] E. C. Freeman, B. Carroll, J. Phys. Chem., 62, 394 (1959).

[21] Ya. Shestak, The theory of thermal analysis: Physical and chemical properties of solid non-organic materials (Mir, Moscow, 1987).

[22] H. E. Kissinger, Analyt. Chem. 29, 1702 (1957).

[23] M. B. Usvitsky, Izv. Acad. Nauk SSSR, Neorg. Mater. 5, 1589 (1969).

[24] M. V. Dobosh, I. D. Turianitsa, in Materialy IV Respublikanskoy konf. po fizike i tekhnologii plenok slozhnykh poluprovodnikov (Uzhgorod, 1981), p. 60.

\title{
ПАРАМЕТРИ КРИСТАЛІЗАЦІЇ НЕКРИСТАЛІЧНИХ ХАЛЬКОГЕНІДІВ СУРМИ
}

\author{
В. М. Рубіш, М. В. Добош, П. П. Штець, І. І. Шпак, В. В. Рубіш, І. М. Юркін, Д. Г. Семак, В. І. Феделеш \\ Ужгородсъкий національний університет, \\ вул. Волошина, 54, Уюггород, UA-88000, Україна
}

Подано результати дослідження кінетики неізотермічної кристалізації стекол системи Sb-S-I. Методами ДТА і ПТА вивчено характеристичні температури теплових ефектів $T_{g}, T_{c}, T_{m}$. Із залежностей температур початку $\mathrm{T}_{C 0}$ і максимуму $T_{C M}$ ефекту кристалізації від швидкости нагрівання $q$ розраховано енергії активації виникнення кристалічних зародків $\Delta G_{A 0}$ і їх росту $\Delta G_{A M}$. Визначено критичні радіуси кристалічних зародків $r_{c}$ і радіуси аморфізації $r_{a}$. Досліджено кристалізаційну здатність сплавів залежно від складу. Показано, що мінімальну кристалізаційну здатність мають склади з ділянок евтектик, а максимальну - склади поблизу стехіометричних сполук $\mathrm{Sb}_{2} \mathrm{~S}_{3}$ i SbSI. Отримані результати обговорено на основі особливостей структури вивчених матеріялів. 